\title{
Finanz-IT im Umbruch
}

Die Größe eines Wortes stellt die relative Häufigkeit in den Beiträgen des Heft-Schwerpunktes dar.

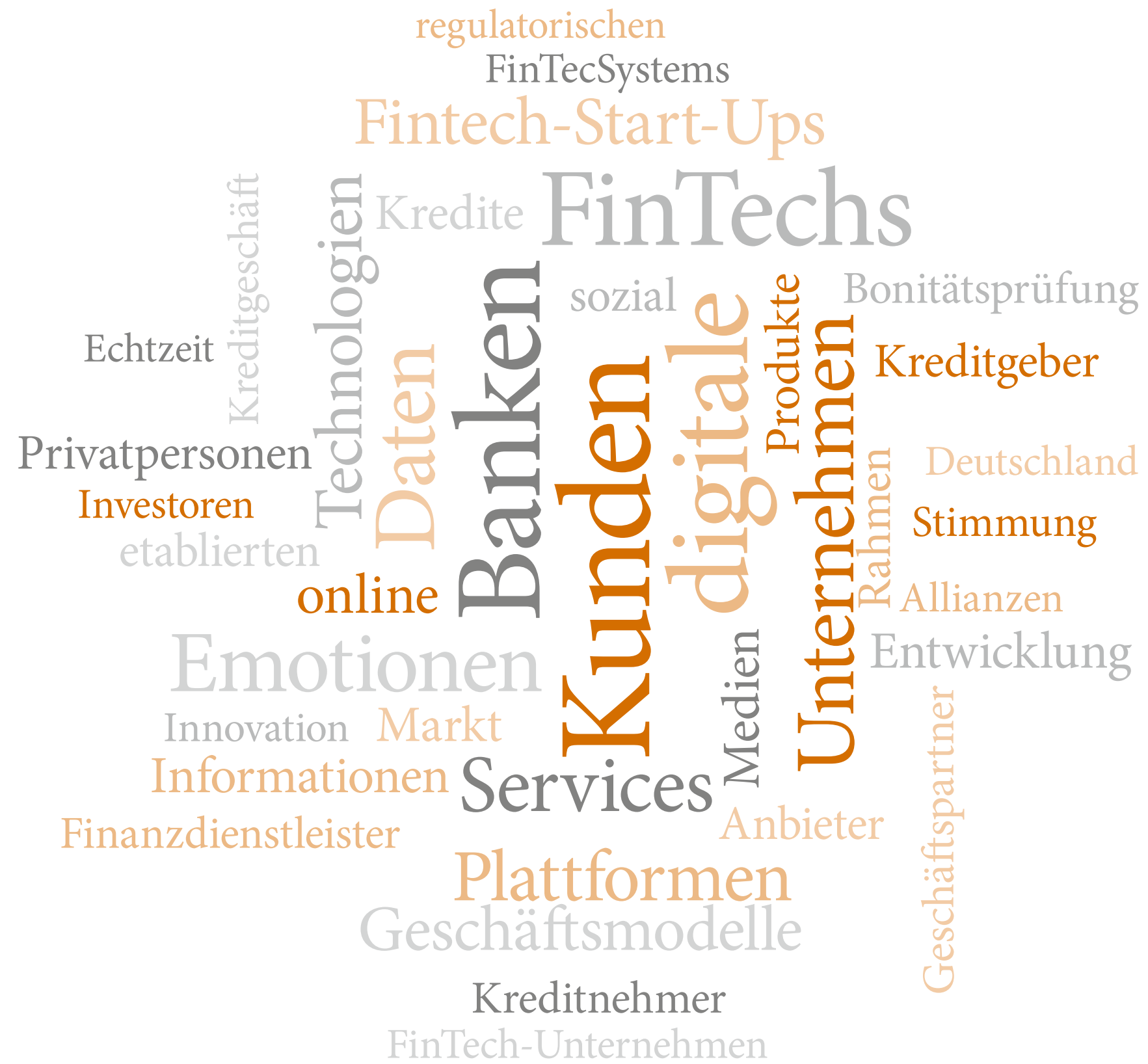

